\title{
The Integration of Music Education Based on Hyperlinks
}

\author{
Cao Hongxing \\ Dept. of education \\ Hefei University \\ Hefei, China \\ e-mail: caoyong1994@163.com
}

\author{
Liu Zhipei \\ Dept. of education \\ Hefei University \\ Hefei, China \\ e-mail: liuzp0223@163.com
}

\begin{abstract}
The course integration is a key breakthrough as to the structure adaptation in the process of New Course Reform. Integration has become the basic feature of the elementary course system. This essay puts up with the conception and technology of integration of music education based on hyperlinks. According to the three levels of course integration in the Standards for Music Course, teaching goals has been designed respectively in this essay.
\end{abstract}

Keywords-hyperlinkst; music meaching; integration; teaching Goals ;

\section{INTRODUCTION}

Early from the autumn of 2001, the reform of elementary course has been gradually put into practice nationwide. With the development of this reform, people's cognition of the goal of the reform becomes clear step by step. It is reasonable to say that reform is a process during which more and more attention is drawn. One of the attention is about the course integration, which was given birth by the weakness of the traditional practice of dividing subjects. The theme of music education is aesthetic. We advocate the concept of "integrity" since it is beneficial to change the fragmentation of our personality into integrity and makes a harmonious development. Our music course shows the principle of curriculum integration in music education. It can help students to understand music more vividly and directly. Meanwhile, it can stimulate students to respect the art and promote them to understand the multiculture and improve their ability of appreciation, expression and creation. During the process of teaching, we need to seize music as the main and basic idea. And we should make full use of the other curriculums except music and let them serve for the music, which can improve the teaching achievements.

The course integration can also be called "course unification" or "subject integration" as well as "curriculum integration". One important goal of the New Course Reform is to strengthen the integrity of the curriculum structure. Integration is the key breakthrough as to the structure adaptation in this reform; it has also become the basic feature of the elementary course system. Three ways are available to realize this integration, they are: to integrate teaching, curriculum and activities. This essay is aimed at researching some problems in the process of integration of music education.

\section{THE INTEGRATION OF MUSiC EdUCATION BASED ON HYPERLINKS}

The conception of course integration calls for a change of the text carrier, that is, from static to dynamic, from isolated to connected, from closed to open, from exclusive to comprehensive. The development of information technology provides the possibility as well as a platform for the practice of curriculum integration. For example hyperlinks connect us through electronic means, thus solving the problem of linkage between text and text, and between media and media. Hyperlinks connect quantities of isolated information, which will later form the Internet information system of hypertext and hypermedia. The amount of information resource that people can get from the hyperlinks is inestimable. The opportunity hyperlinks set for the project of course integration in the 21-th century's education can not be better.

In reality, countless communications exist between the art of music and other subjects. Such communications should be taken good advantage of to establish even broader linkages with painting, literature, history, geography and so on. For instance, when we learn to sing the song of Santa Lucia, it is great to inspire students to get relevant knowledge through hyperlinks, see Fig.1.

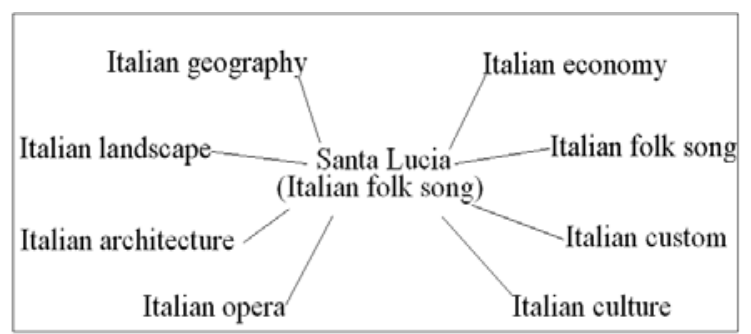

Figure 1. The graph of hyperlinks.

We can imagine how broad and ample the subjects related to a folk song are from the diagram above. This not only broadens students` horizon, but cultivates their interests and hobbies, more importantly is that during this process students are able to draw inferences about other cases from one instance. This process therefore, gives students the message that all things in the world are universally connected. Additionally, it supplies the students with a huge room to imagine around, to innovate. 
Of course, this kind of hyperlink is not a talk at random, instead, it has solid purposes. The Standards for Music Course advocates three levels of basic conceptions of the course integration, correspondingly there are three clear teaching goals, see Fig.2.

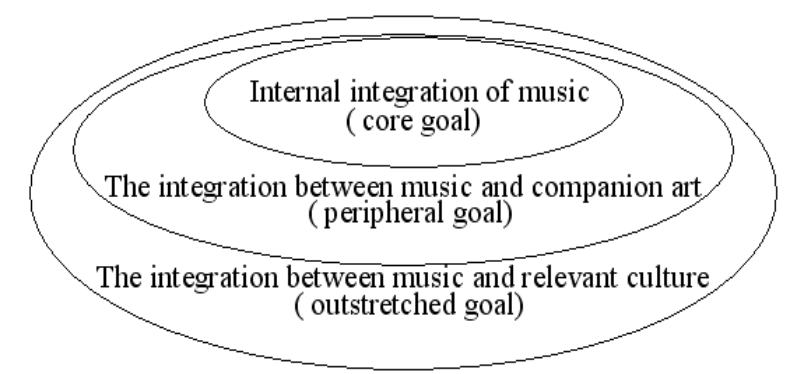

Figure 2. The diagram of course integration and the teaching target

First, the integration between different teaching fields in the subject of music, like singing, playing instruments and music appreciation, this is the core goal of teaching integration. It was set with the intention to inspire students ability to connect horizontally, broaden music horizon and improve their music taste. In light of the nature of this subject, this is a must for students to master; in light of enhancing students creativity, this is the fundamental requirement. In the standard of music course, it emphasizes that "the integration which is based on music is a kind of colorful music art and a variety of music performance. The related culture provides students with the goal of experiencing, exploring and studying and it is also the main content and process. What's more, it does not mean that we casually combine the related culture with other curriculums. So when choosing the integrate materials, teachers should consider whether the materials are based on the music. In the standard of course which mentions the course integration, we clearly illuminate the idea that the integration must put the music as the main teaching goal and we should use the specific materials to establish the connection of music and other arts or curriculums. So during the teaching, whatever the combination of music and related arts or music and other curriculums, it must reflect the music when appreciating the March of the Volunteers, in order to let students understand the background of the national song and know the meaning of it. I introduce the story of the national story by combining the history and videotapes. And then I let them see the red flag which is rising from the Tiananmen Square while listening to the music. It can make students understand the solemn meaning of the national song. Through the short time of listening to the story and watching videos, it can arouse the students' imagination: where can you hear the national song? What are your feelings? And then students may develop the feeling of excitement and pride, so they can respect and praise the national song from the bottom of their hearts. Similarly, in the latter study of "triplet" and "accent", I use the video of the battlefield which is full of smoke of gunpowder and let the students imitate the "DaDaDe" of gun to master the meaning of triplet and imitate the "honghong" of artillery to master the meaning of accent. And meanwhile, through the short time of video, we can integrate the emotion into the study if music and the students can know and understand music from the sensory point.

Secondly, the integration between music and companion arts, like dancing, opera, painting and filming. The aim of this kind of integration is to make students able to thirl through and shift smoothly in different fields so that their aesthetic taste can be improved, this aim is the peripheral goal. According to the core goal, it is required that teachers leave enough space in their teaching plans to students as to contents, width and the extensibility and amalgamation of the subject. Teachers should also provide research subjective hint, encourage students to develop their consciousness and play an active part. This is also the process that students should undergo to solve problems with a comprehensive ability, a new way to seek to resolve dilemma. In the teaching of appreciating the "great storm on the sea”, we can properly integrate the teaching of art into it. The students can use the line and color to draw what they hear from the music, such as wind, downpour and lightening. The children are imaginative. When we present what whey draw on the backboard, and meanwhile play the music, it can further make student learn the music. Also, in the appreciation of "I can a cavalry on the grass land, we can first teach students some simple action of horse riding and sentry and then illuminate them to have performance when listening to the music. The students dance happily with music; some perform action of cracking the whip. Through the expression of body language, students are in a high spirit, which paves a way for the teaching of song.

Third, the communications between music and relevant subjects such as literature, history, geography, race, custom and religion, it is to broaden students `cultural horizon and to improve their imagery thinking and abstract thinking ability. This is the outstretched goal which lies more on selfstudy and self-development. In the teaching of "seeking spring", we can use the method of combing of music with other curriculums, such as literature, art, dance and so on. Based on the understanding of music, we can organize students to have a discussion and use their favorite ways to present the spring. The students are all smart and energetic. So we can use many ways to arouse passion of loving wife, loving nature and loving art, meanwhile, we also arouse their desire to show and inspiration to create and cultivate their overall quality.

\section{CONCLUSION}

Music is a kind of social and cultural phenomenon and its aesthetic activity is based on the social life and has a great connection with other curriculums. Using course integration in the process of music teaching mode and provide abundant teaching resources for the music teaching, 
but make the music class active and strengthen their understanding of music. As for our teachers, we should keep up with the pace of the times, update our teaching ideas constantly, broaden our vision, and break the concept of curriculum. During the teaching process, we need to practice bravely of creating the teaching structure and the whole teaching method. Only by doing so can we better make the full advantage of interdisciplinary. We can broaden the aesthetic vision of students, fully experience the beauty of music, edify the emotion, enlighten the wisdom and let the personality develop into integrity. So we can promote the development of the music education teaching in our country. In conclusion, course integration is an integration with only music being the center, rather than multi-centered and even priority-misplaced. It penetrates through every loop of teaching instead of partially linked. On top of this, the category of attribution of art education should be emphasized when carrying out the course integration, otherwise the process would get out of track. The ultimate consequence may be the recognition of music as a subject totally irrelevant to art, thus the integration would lose all the meaning centered on or connected with music.

\section{REFERENCES}

[1] M.Y. Liu Mingyuan, "Who will teach Comprehensive course in 21 Century---How to Reconstruct The New Curriculum Structure”. Peking University Press, 2002, pp.65-76.

[2] Standard about The Music Curriculum,3rd ed .Ministry of Education in China, Beijing Normal University Press,2001.

[3] P. Liu, "Overview of Practice and Theoretical Research on the Music Education”.Shanghai Music Press, 2004, pp.34-43.

[4] L.Gao, "Media and information technology", Peking University Press, 2002, pp.145-149.

[5] Having a Conversation with Implementers about The New Curriculum, Department for Basic Education under the Ministry of Education, Beijing Normal University Press, 2002. 